\title{
Kazakh-China Energy Strategic Partnership Deepens
}

\author{
Zhanna Dossan ${ }^{1}$ \\ ${ }^{1}$ School of Political Science and Public Administration, Wuhan University, Wuhan, China \\ Correspondence: Zhanna Dossan, School of Political Science and Public Administration, Wuhan University, \\ Wuhan, Hubei, 430072 China. E-mail: zhanna.dossan@gmail.com
}

Received: November 28, 2019

doi:10.5539/jpl.v13n2p122
Accepted: April 10, 2020

Online Published: May 25, 2020

URL: https://doi.org/10.5539/jpl.v13n2p122

\begin{abstract}
Strategic partnership between Kazakhstan and China has significantly increased in the last two decades. The SinoKazakh bilateral relationship has considerably extended in terms of economic, political and security particularly after the collapse of Soviet Union. Especially both countries have great prospects for cooperation in the energy sphere. But the energy future of these countries carries a great potential for change, which is related to the shortage of global energy resources. Dialogue between the two countries in the sphere of extraction and use of energy resources will be determined by the political and economic situation on the Eurasian continent. Furthermore, the study concludes that the relationship between the two countries should be beneficial and transparent not equaovocal in nature.
\end{abstract}

Keywords: energy cooperation, China, Kazakhstan, economic partnership

\section{Introduction}

It is observed that strategic partnership between China and Kazakhstan signed on $4^{\text {th }}$ July 2005 is now expanding due to lot of focus on political, security and cultural relationships (Javaid and Dashti 2017). President Hu Jintao agreed to develop a strategic partnership with Kazakhstan, which included an increased focus on increasing bilateral trade between the two nations. It is also agreed that bilateral meetings will be carried out between the two nations regularly. The observations were made that Kazakhstani sinologists came out with the arguments that these relationships should be increased, because both the nations carry a lot of potential in terms of maintaining an adequate platform of trade.

It was clear that Beijing and Nursultan prepared a whole report by aiming to improve the trading activities between the two nations. This aimed to increase the trade between the two nations by showcasing the challenges and their business opportunities. The findings of the visits made to Nursultan by the president of China, foreign minister Cheng Guoping announced that relationships between the two nations would be increased (Besada and Salam 2017). Both nations have observed bilateral relationship building in different sectors because the trade volume reached a value of more than $\$ 20$ billion. This was due to expanded trading activities in political mutual trust-building between the two nations. For example, investment in different areas included security and energy sector and other close co-ordinations between the two nations under many multilateral frameworks. For example, it was announced that the China-Kazakhstan Horgos International Border Cooperation Center will start operating soon to provide the activities platform to people of both the nations (Ibid:7). Furthermore, this framework of development has also been observed among other nations to ensure that trading activities are according to the requirements.

\subsection{Problem Statement}

It is observed that relationship between the two nations has significantly increased because both the nations have resources, which can be exchanged between the two nations. However, some studies are concerned as to where this friendship would lead towards higher level. This high interaction between the two nations is increasing the risks of low investments if relationship between the two nations goes down (Behera and Gubaidullina 2018). China and Kazakhstan both have long-term relationships planned ahead; that's why more trusted cooperation then chances to winning the revenues would significantly increase.

This research paper aims to understand the relationship challenges between China and Kazakhstan in terms of energy sector challenges. Furthermore, it also aims to find out the chances of losing the revenues in case the relationship between the two goes down. Most of the times both these nations have been able to establish 
diplomatic ties, however, if sometimes this relationship weakens, it will become difficult to revive it (Behera and Gubaidullina 2018). Currently, the investment volume between the two nations has reached a value more than $\$ 30$ billion. Hence China has become a major trading partner of Kazakhstan in this region, and most of the economic revenues of Kazakhstan are depending on energy sector relationship with China. This research aims to analyze the energy cooperation of China with Kazakhstan and what are its mutual benefits. Therefore, following questions are investigated in this research:

1) What is the reason that Kazakhstan is looking towards China in terms of energy strategic partnership?

2) What are the risks involved in relationship between these two nations and their consequences in energy sector?

\section{Method}

A high number of methods are available to the investigators, which can be used for data collection; however, it must be selected adequately after critical evaluation of the objectives. Thus, section of paper, explains the methods used for the investigation and to present the analysis section. This section is divided into subheadings for clear understanding of the methods, and the reasons behind selection. Some of the most important sections of methods are explained here, which include research context, methodology, procedures, analysis methods, and sample size.

\subsection{Research Context}

There are many research methods, which can be used by the authors, but research context should be identifying the main arguments, which are according to the topic. The research context of this study is based on explanation of the arguments, which are related to the relationship between China and Kazakhstan, in terms of energy sector. The arguments are mostly related to explanation and critical evaluation of the relationship between the two nations. The research context only emphasizes on the relationship between China and Kazakhstan in the energy sector, and how it is related to the development of both the nations. Although China is maintaining relationships with many nations of Central Asia, the focus of this study is only on relationship with Kazakhstan and in energy sector.

\subsection{Research Philosophy}

There are many research philosophies available to the investigators given below:
1) Ontology
2) Positivism
3) Interpretivism
4) Epistemology
5) Realism
6) Axiology

This research makes use of realism approach for investigation because it was the most appropriate in terms of presenting the arguments on different trading relationship between the two nations. The concept of realism was developed in 1930s and 1940s as an alternative to attempts to understand and conduct international relations based on international law. Realism approach is considered the most appropriate when it comes to analyzing the arguments by observing only the qualitative statements. The first assumption of realism is that the nation-state (usually abbreviated to 'state') is the principle actor in international relations. Other bodies exist, such as individuals and organizations, but their power is limited. Second, the state is a unitary actor. National interests, especially in times of war, lead the state to speak and act with one voice. Third, decision-makers are rational actors in the sense that rational decision-making leads to the pursuit of the national interest. Here, taking actions that would make your state weak or vulnerable would not be rational. Realism suggests that all leaders, no matter what their political persuasion, recognize this as they attempt to manage their state's affairs in order to survive in a competitive environment. Finally, states live in a context of anarchy - that is, in the absence of anyone being in charge internationally. The often-used analogy of there being 'no one to call' in an international emergency context helps to underline this point. Within our own states we typically have police forces, militaries, courts and so on. In an emergency, there is an expectation that these institutions will 'do something' in response. Internationally, there is no clear expectation of anyone or anything 'doing something' as there is no established hierarchy. Therefore, states can ultimately only rely on themselves. It has become easier for the authors to increase the investment in understanding the relationship between the two nations through this framework. 
Realism approach is further divided into 2 different types, which are direct realism and critical realism approach; however, it is necessary that all of them should be used by the investigators to understand the relationship between dependent and independent variables.

Realist theorists argue that politics should view as it currently exists, and not how one would wish the world were. And when looking at the political system, or more specifically, the international system, realists focus their ideas about how international relations work based upon the concepts of power and security. The greatest strength of Realism in this region is that it holds most relevance when describing the areas tumultuous political system. Structural realists believe the primary goal of any state is survival. How does a state survive? It must have the military capabilities to protect itself from any attack. This notion is reiterated by Iran's recent threat to build a nuclear weapon particularly and generally by many countries. World leaders such as David Cameron have claimed that it could instigate an arms race in the region. "I think it could trigger a nuclear arms race across the whole region. That would make the Middle East a more dangerous, more unstable part of the world." Another aspect of Realism that could be strength if implemented is the Realist theory in the ethnic realm. This theory simply argues that when ethnic communities become extremely hardened by conflict, "ethnic separation, both physical and political, is necessary to prevent endemic bloody ethnic conflict and chronic instability" (Ben-Porat 2008).

Realism has four main weaknesses. Three of these weaknesses, which inspire much of the criticism against Realism, appear at what Waltz identifies as the human and state levels of analysis. First, Realism has typically relied on a gloomy view of humans derived from assuming a supposedly unchanging conflict-prone 'human nature.' This leads to the second weakness, a tendency to treat politics both within and between states as involving unending competition for advantage. Third, Realists lack clearly articulated theories of how governments of states (or any other type of actor) make decisions. The fourth weakness spans the state and international system levels, and consists of insufficient attention to the increased influence of non-state actors resulting from changes at both of those levels in the last 150 or so years. Conversely, Realism's continued strengths derive from the attention Realists pay to the structure and the process at the international system level. The shape of that system level does not directly determine the choices of governments and other actors, but it does constrain their choices significantly and shape the outcomes of their interactions. Each of the next three sections focuses on one of Waltz's levels of analysis, outlining how Realists address each and indicating the weaknesses and strengths of Realist approaches to phenomena at that level.

Out of the two methods of realism approach namely direct realism and critical realism, this research aims to find out the relationship between China and Kazakhstan by using critical realism approach. Critical realism approach helps in identifying the relationship between the two nations by critically observing their intentions towards the development of good relationships in energy sector. This research presents a desk review of the arguments presented by different research papers on relationship between China and Kazakhstan.

\subsection{Measures}

The measures which should be undertaken by the investigators must be according to the results needed to be achieved. These measures should be taken after careful consideration of the objectives; otherwise, results validity and reliability will decline. In order to find out the results of this study, only the research articles available in the last 10 years will be used. This will allow the collection of data, by providing the latest trends which have been observed in relationship building of China and Kazakhstan. Furthermore, it will allow understanding the energy relationship between both the nations and the strategies they should take to help each other

Another important measure undertaken for this investigation is the selection of the research articles by using Google Scholar website. This research article aims to identify the role of China and why it is investing in energy department of Kazakhstan, because, it is important to use only the research articles understanding the relationship between these nations.

\subsection{Procedure}

This study followed an appropriate procedure for data collection and analysis and to understand the relationship between China and Kazakhstan with proper guidance and realism approach. First of all, research questions of this study were identified, because it is considered one of the most important parts for data collection. At second instance, it was checked, whether the questions were according to the research aims and objectives of this study.

\footnotetext{
${ }^{1}$ http://www.express.co.uk/posts/view/356381/Iran-could-trigger-nuclear-arms-race-warns-David-Cameron

${ }^{2}$ The Failure of the Middle East Peace Process: a comparative analysis of peace implementation in Israel/Palestine, Northern Ireland and South Africa by Guy Ben-Porat 2008
} 
The questions and aims of this study were shown to the supervisor to check whether they were appropriate. This assisted in understanding, whether the research aims and objectives were valid and reliable.

Once research articles and questions were collected, it became easier to analyze, whether the performance of both the nations was appropriate. It became easier to analyze whether China and Kazakhstan were appropriate for the investigation. Next research articles were collected for carrying out critical review. However, before carrying out desk review, it was ensured that each article was according to the topic theme. After that statements were drawn out of those research articles for comparison. It was quite a difficult task and demanded that flow during data analysis is not influenced. After critical review of the arguments, it was ensured that flow and arguments under each heading were according to the requirements, and meeting the compliance with research questions.

Once the results were analyzed, the conclusion part came out by the author. Reason to write discussion and conclusion part was to allow the readers get a summary of research findings. It is quite difficult task to write conclusion and present the results in summarized form. Therefore, after writing down the conclusion part, it was shown to supervisor so he can check, whether it contained everything related to the research questions. With the help of research questions, it became easier for the researcher to collect data and present appropriate results in the form of summary.

\subsection{Data Collection Method}

This research made use of qualitative approach for data collection and analysis. For collecting qualitative data there are many methods available to the investigators, such as interviews, case studies, observations. However, this research made use of qualitative approach for meeting the demands of a research paper. The quantitative approach is not suitable for this study, because most of the people did not know about the reasons China and Kazakhstan are maintaining relationships with each other in energy sector.

\subsection{Data Analysis Methods}

Data analysis methods are available in many forms and it has become necessary that all of them should be evaluated after observing the requirements of the research paper in order to increase validity and reliability. Data analysis methods are mostly available in many forms but segmented into qualitative and quantitative forms, however, selecting the best one of them is necessary. The method selected for this research paper was qualitative in nature because the topic of this study was pretty unique and demands the understanding of all the concepts needed for understanding the Kazakh-China Energy strategy partnership. Method selected for the analysis is desktop literature review approach because it is the best method behind this research.

With assistance of this research analysis method, it became easier to evaluate deepening relationship between Kazakhstan and China, in terms of energy relationship. The scholars were selected from Google Scholar website because it is considered one of the most authentic websites when it comes to selecting a research article for analysis and comparison. By using this method of analysis, this research presents critical literature review by analyzing both positive and negative perspectives of this Kazakhstan and China relationship in energy sector. In addition, only research articles presented in the last 5 years were selected for review. The review of all the articles was done critically because it helped in analyzing the strategic partnership between the two nations based on past experience and predicting them for future.

\subsection{Sample Size, Sampling Method and Population}

Sample size, method and population of an investigation are considered one of the most important parameters when it comes to observing the critical review of the forces. Sampling methods are available in many forms and segmented into probability sampling methods and non-probability methods. This research makes use of non-probability sampling method because it provides the assessment of all the research objectives in detail. Non-random sampling methods are available in many types; however, the one utilized in this study is purposive sampling method, because it provides the assessment of all the results by observing the results based on a purpose.

Purposive sampling method was used because it allowed in selecting research article based on the topic of investigation. For example, only the research articles addressing the energy relationship between Kazakhstan and China were selected. In addition, the sample size of research articles were 15-20 articles for critical review. This sampling method assisted in selecting the most relevant articles related to the topic. It also assisted in understanding the role of different scholars, and the reasons they involved themselves in understanding deepening relationship between Kazakhstan and China. Another important consideration which was undertaken for critical review of the articles was selected during the last 5 years. The relationship between China and 
Kazakhstan deepened in the last 10 years (Xu et al., 2017), therefore, this research selected scholarly articles within the last 5 to 10 years. This also increased validity and reliability of the findings.

\section{Data Analysis}

This section is divided into different headings and sub-headings based on critical review of the arguments related to Kazakhstan and China relationship in energy sector.

\subsection{Strategic Partnership between Kazakhstan and China in Energy Sector}

According to historical trends, the relationship between Kazakhstan and China started to develop in energy sector. During Soviet Union period, both these nations' only followed informal trading activities, but after independence of Kazakhstan, new lands of trades were established between the two nations (Javaid and Dashti 2017). This was the time when strategic partnership between the two nations started to develop, because Kazakhstan is rich in energy resources, whereas China is the largest product manufacturer in the world. However, it is argued that more interest was shown by the companies operating in China as compared to Kazakhstan because they wanted to overcome their problems of energy (Indeo 2018). In this era of globalization, where the issues of economy matter so much, China and Kazakhstan seek to increase their energy relationships.

A vast number of energy resources are present in Kazakhstan, but China has more trading activities in globe, due to which Kazakhstan look forward to China. Several reports say that energy resources in Kazakhstan are not helping it to overcome the issue of landlocked (Ho 2017). Therefore, it became necessary for Kazakhstan to develop a pipeline for transportation of these energy resources and get something in return from China. Supporting the statement, (Xu et al., 2019) stated that after dissolution of the Soviet Union, China has been helping Kazakhstan by increasing the discoveries of all the energy resources of Kazakhstan.

There is a considerable amount of hydrocarbon in Kazakhstan, which was discovered by China. It is observed that people working in different nations are willing to build strategic partnership with China because it has a large number of resources, which can be used by nations around the world. The performance of all the nations in the world is depending on energy demands, because energy consumption of this era is quite diversified (Ho 2017). However, China is in need of vast energy resources. While the world is being controlled by other nations such as USA, it has become difficult for China to become a superpower. Due to this reason, China is aiming to become a major player in the globe without taking inappropriate approaches. In an investigation presented by (Xu et al., 2019), the authors argued that Kazakhstan is facing intense competition from different oil-producing nations, due to which, it is aiming to increase its relationship with in energy sector. However, it is necessary that Kazakhstan should be aware of the fact that China has little time but a helping nature.

Energy producing nations are mostly present in regions like the Middle East, West Africa, East Asia, North Africa and Latin America. According to the article of Besada and Salam (2017), Energy resources present in Kazakhstan are easily available to China as an outside player, without the interference of any other nation (Besada and Salam 2017). The very study further added that Kazakhstan is also willing to take help of China in order to overcome the issues of its economy (Ibid: 5). Furthermore, energy resources of Kazakhstan are constant and helping China in the development of its economy, along with the performance parameters improvement in the workplace. It was observed that major relationships between Kazakhstan and China started to evolve when inauguration of oil pipeline in 2005 took place between the two nations.

Some studies added that Kazakhstan is willing to develop strong relationship with China because it needs raw materials, not available in Kazakhstan. (Behera and Gubaidullina 2018). They also added that in this regard, the formation of Shanghai Cooperation Organization (SCO) developed (Ibid: 9). This corporation has partnership with two major energy producers, in Russia and Kazakhstan, which are acting as the resources for these two nations.

\subsection{China as a Strategic Major Player}

The presence of China in Kazakhstan has been observed from an economic angle, and largely based on energy security needs of this nation. The argument made by (Behera and Gubaidullina 2018) that since Kazakhstan has proven energy resources, oil reserves and natural gas reserves, it is observed that natural gas reserves are needed by China to resolve its issues. Strength of Kazakhstan is rich energy resources, due to which it has observed a boost in its economy in the last few years. However, it is stated that this is because of the reason that China is investing heavily in the development of new energy infrastructures in Kazakhstan, and also supporting Kazakhstan's economy in return (Javaid and Dashti 2017). At the same time, Kazakhstan, which is suffering from oil problems, is taking help of China by deepening the relationship.

China's aim is to become a properly developed nation of the world along with the aims of next superpower. For 
that purpose, it is cooperating with nations of Central Asia, including Kazakhstan to promote regional economic stability and prosperity. This investment will lead to political stability, because China wants to become a stable nation, with peaceful and stable international trade (Tripathi 2017). However, it is simply not possible for China to make this world economically stable, because it lacks in some department of resources available for the support of all the nations (Kenderdine 2018). Nevertheless, Kazakhstan wants to help China in achieving these aims by promoting trading activities (Bitabarova 2018). Kazakhstan is helping China to become a superpower nation of this world by providing them the support through energy resources.

Presence of China in Kazakhstan and Kazakhstan in China is increasing with a rapid pace since articulation of Westward strategy by president of China. New Silk Road economic belt is one of the major influencing initiatives because China wants to increase its relationship with countries of Central Asia, with Kazakhstan topping the list (Ibid: 03). Due to this reason, it has been observed that Kazakhstan has been making the investment in different nations and China sitting on top of the list. Furthermore, if China supports Kazakhstan then Kazakhstan would have high support and power (Orazgaliyev 2017). Therefore, several scholars have recommended Kazakhstan not to develop strong relationship with China and also develop some strict policies to stop unusual interference of China in political matters.

\subsection{A Critical Review of Depth of Relationship between Kazakhstan and China in Energy Sector}

It is observed that Kazakhstan has gone very deep in relationship with China, which can result in many benefits for it in future. Approximately 22 energy organizations of China are operating in Kazakhstan, due to many cooperation were noted by leaders as a model of two states. Continuous cooperation of those countries, with its partners and friends, shows the active promotion the development in a higher level (ShuHong Yu, Zia-ud-din Malik, 2018). The share of Chinese companies in Kazakhstan is expected to reach to more than $40 \%$ by the end of 2020, while shares of Kazakhstan is $10 \%$ and increasing in China (Zhang et al., 2017). Based on these assessments, it can be argued that China is willing to invest in Kazakhstan in order to get a hold on energy resources of Kazakhstan, and is also providing many things back in return.

In some studies, it was evaluated that performance of China is depending on investment in Kazakhstan because if the investment is heavily done, chances of acquiring mutual benefits will increase. Kazakhstan's investment in China $\mathrm{n}$ energy sector is based on four factors (Larcon 2017). The first one is to meet its problems by maintaining sustainable relationship with China. The second one is that Kazakhstan wants to establish its culture and ethno-religious nationalism culture in different regions of Kazakhstan. Furthermore, Kazakhstan wants to deepen its relationship with China to protect its political and economic perspectives (Fiedler 2018). The last factor to maintain good relationship with China is to sell its consumer goods in China (Laurelle 2015). Therefore, these are some of the reasons China and Kazakhstan aim to maintain deep relationships in energy sector.

\section{Discussion and Conclusion}

The purpose of this research paper is to investigate the reasons Kazakhstan is deepening its relationship with China in energy sector. It was observed that Kazakhstan and China both are heavily investing in energy sector, and other sectors to support economic development. For that purpose, critical literature review method was selected, and articles were selected from Google Scholar website were selected during the last 5 years period. It is observed that there are many reasons behind investment of Kazakhstan in China specially to build strategic partnership.

Firstly, Kazakhstan needs economic assistance of China along with policy development guidance. Kazakhstan was heavily relying on Russia previously and now wants to establish another partnership. This is also one of the reasons behind Kazakhstan's relationship with China. One more conclusion drawn from the discussion is the fact that Kazakhstan needs to increase its presence in China by selling its products in China. Although China has always aimed to help Kazakhstan for the development of new alternatives in energy sector, China has not been allowed penetration to a major extent. China will be reaching a mark of $40 \%$ shares in Kazakhstan's economy, while, Kazakhstan's investment is not even $10 \%$. Therefore, these are some of the reasons behind high interest of Kazakhstan in China and also of China in Kazakhstan in energy sector.

\section{Acknowledgments}

I acknowledge that this study was carried out by me as a sole writer. I would like to acknowledge that content taken from any other source has been acknowledged with proper referencing.

\section{References}

Behera, A., \& Gubaidullina, M. (2018). Between China and India: Energy Dimension of Kazakhstan. ХАБАРШЫ, 4. https://doi.org/10.26577/IRILY-2018-1-760 
Besada, H., \& Salam, J. (2017). China's Energy Strategy in the MENA Region. China Quarterly of International Strategic Studies, 3(04), 597-619. https://doi.org/10.1142/S2377740017500269

Bitabarova, A. G. (2018). Unpacking Sino-Central Asian engagement along the New Silk Road: a case study of Kazakhstan. Journal of Contemporary East Asia Studies, 7(2), 149-173. https://doi.org/10.1080/24761028.2018.1553226

Fiedler, R. (2018). Central Asia on the way of One Belt, One Road-implications for the European Union. Rocznik Integracji Europejskiej, (12), 255-266. https://doi.org/10.14746/rie.2018.12.17

Ho, S. (2017). China's transboundary river policies towards Kazakhstan: Issue-linkages and incentives for cooperation. Water international, 42(2), 142-162. https://doi.org/10.1080/02508060.2017.1272233

Indeo, F. (2018). The Impact of the Belt and Road Initiative on Central Asia: Building New Relations in a Reshaped Geopolitical Scenario. In China's Belt and Road Initiative (pp. 135-153). Palgrave Macmillan, Cham. https://doi.org/10.1007/978-3-319-75435-2_8

Javaid, F., \& Dashti, A. A. (2017). Sino-Central Asian Relations and Sino-Us Rivalry in the Region: A Study. Grassroots, 51(1).

Kenderdine, T. (2018). Kazakh Land, China Capital: Exporting China's Project System to External Geographies. Central Asian Affairs, 5(4), 313-341. https://doi.org/10.1163/22142290-00504002

Larçon, J. P. (2017). The economic impact of China on the Baltic Sea region. Centrum Balticum BSR Policy Briefing series.

Laruelle, M. (2015). The US Silk Road: geopolitical imaginary or the repackaging of strategic interests? Eurasian Geography and Economics, 56(4), 360-375. https://doi.org/10.1080/15387216.2015.1098555

Orazgaliyev, S. (2017). Competition for pipeline export routes in the Caspian region: The new Great Game or the new Silk Road? Cambridge Journal of Eurasian Studies, 1, 5B75G8. https://doi.org/10.22261/5B75G8

Yu, S., \& Zia-ud-Din, M. (2018). International Trade Agreements and Their Relation to Core Labor Standards. $J$. Pol. \& L., 11, 33. https://doi.org/10.5539/jpl.v11n3p33

Smith Stegen, K., \& Kusznir, J. (2015). Outcomes and strategies in the 'New Great Game': China and the Caspian states emerge as winners. Journal of Eurasian Studies, 6(2), 91-106. https://doi.org/10.1016/j.euras.2015.03.002

Tripathi, A. (2017). The Great Game that Never Ends: China emerges as leading player in Kazakhstan. Artha-Journal of Social Sciences, 16(4), 61-78. https://doi.org/10.12724/ajss.43.4

Xu, Y., Mai, J. W., Yu, B. J., Hu, H. X., Yuan, L., Jashenko, R., \& Ji, R. (2019). Study on the Genetic Differentiation of Geographic Populations of Calliptamus italicus (Orthoptera: Acrididae) in Sino-Kazakh Border Areas Based on Mitochondrial COI and COII Genes. Journal of economic entomology. https://doi.org/10.1093/jee/toz112

Zhang, H., \& Li, M. (2018). A process-based framework to examine China's approach to transboundary water management. International journal of water resources development, 34(5), 705-731. https://doi.org/10.1080/07900627.2018.1476225

Zhang, H., Li, M., Zhang, H., \& Li, M. (2017). 11 China and global water governance (pp. 219-237). London; New York: Routledge.

\section{Copyrights}

Copyright for this article is retained by the author(s), with first publication rights granted to the journal.

This is an open-access article distributed under the terms and conditions of the Creative Commons Attribution license (http://creativecommons.org/licenses/by/4.0/). 